\title{
Buridan's ass syndrome: Dilemma of the human resources practitioner in workplace bullying
}

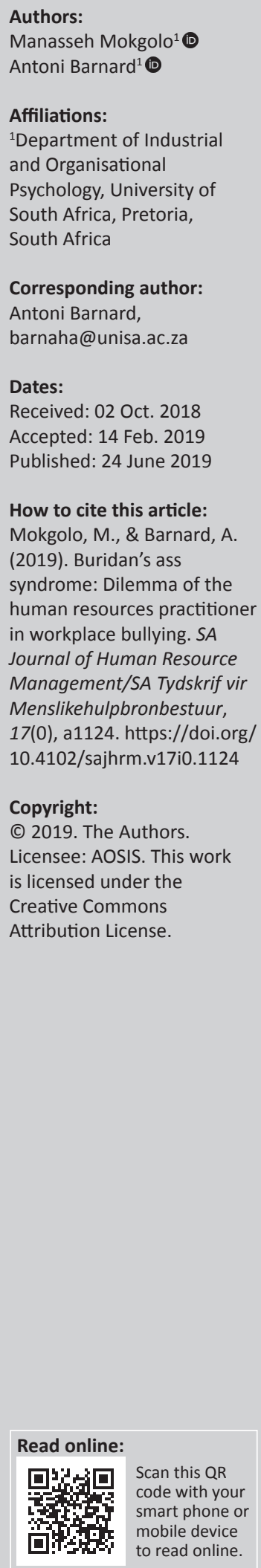

Orientation: Worldwide, bullying in the workplace is recognised as a sensitive and psychologically destructive issue. It has a detrimental effect on employee well-being, organisations' productivity and employee relations. As a vital link between different constituencies in the organisation, human resource practitioners struggle in their attempts to address and manage workplace bullying.

Research purpose: The aim of this article was to describe the challenges that human resource practitioners face when being tasked with addressing workplace bullying.

Motivation for the study: Concern about human resource practitioners' capacity to manage situations of workplace bullying requires a better understanding of their role in and perspective of the bullying phenomenon.

Research approach/design and method: A constructivist, grounded theory research design was used to explore the perspectives of nine human resource practitioners on workplace bullying. Data were gathered through semi-structured interviews to gain insight into and understanding of their experiences of bullying in the workplace.

Main findings: Paradoxical role demands, lack of decision-making power and their perceived lack of support from policy and management disable the human resource practitioners' functionality in addressing workplace bullying.

Practical/managerial implications: The study identifies dilemmas that human resource practitioners face, impeding their capacity to address workplace bullying effectively. Findings highlight the practical value of empowering such practitioners in the role they play in dealing with workplace bullying situations.

Contribution/value-add: The present study contributes to the limited body of knowledge on human resource practitioners' perspectives on workplace bullying within the South African context.

Keywords: workplace bullying; counterproductive work behaviour; human resource practitioner; critical realism; constructivist grounded theory; theoretical sampling; Buridan's ass.

\section{Introduction}

Human resources (HR) is increasingly being regarded as a strategic partner providing support for various employee matters to management, line managers and employees (Heizmann \& Fox, 2017; Paauwe \& Boon, 2018). The HR function includes strategies to retain employees as valuable assets (Davis, 2017; Galang \& Osman, 2016), to ensure optimal employment relations and to enhance employee wellness (Collings, Wood \& Szamosi, 2018). Human resources practitioners therefore play an undeniably important role in maintaining optimal workplace relations and well-being (Collings et al., 2018). This is especially true because disruptive behaviour such as workplace bullying has become a frequent occurrence that they have to deal with (Salin et al., 2018). Human resources practitioners, however, face numerous obstacles in their attempt to prevent and address unacceptable and inappropriate workplace behaviour, such as bullying (Fox \& Cowan, 2015).

Workplace bullying is classified as counterproductive workplace behaviour (Fox \& Spector, 2005) and poses a direct threat to the wellness of employees and the organisation as a whole (Nzonzo, 2017). For employees, such misbehaviour leads to reduced work performance, lower job satisfaction, poor interpersonal relationships as well as decreased motivation and morale (Coetzee \& Van Dyk, 2018). The organisation suffers costs because of more frequent staff turnover and increased absenteeism (Sheehan, McCabe, \& Garavan, 2018). Still, the prevalence of bullying in 
the workplace is increasingly acknowledged globally, and organisations should ensure its effective management (Dzurec, Kennison, \& Gillen, 2017; Salin et al., 2018; Van Schalkwyk, Els, \& Rothmann, 2011).

Human resources practitioners play an integral part in managing situations where workplace bullying takes place (Branch, Ramsay, \& Barker 2007; Salin et al., 2018). Such practitioners are not only expected to assist targets with their complaints but also to investigate bullying incidents and enforce the organisation's policy in this regard (Salin, 2008). Despite substantial literature on workplace bullying, HR practitioners' perspectives of the bullying phenomenon within organisations is largely absent in research (Cowan, 2012; Fox \& Cowan, 2015; Salin et al., 2018). By engaging an HR practitioner perspective, organisations may gain an understanding of their capacity to manage bullying situations appropriately and effectively. The management of counterproductive behaviour such as bullying in the workplace cannot be operationalised fully and efficiently without considering the HR function's role and its interrelationship with employees and management in the organisation (Jackson, Schuler, \& Jiang, 2014).

The present study explored workplace bullying from the point of view of HR practitioners tasked with identifying and dealing with such misbehaviour in the workplace. The primary purpose of this article is to report on the dilemmas that HR practitioners face in this context.

\section{Workplace bullying}

The study of workplace bullying finds its roots in the investigation of bullying behaviour among schoolchildren in the 1970s (Olweus, 1978). In the early 1980s, the focus changed from schoolchildren to the work context and adult victimisation (Leymann, 1990). Adult bullying at work was conceptualised as 'workplace bullying' by Andrea Adams in 1990, who publicised the significance of bullying at work and its hostile influence on people's lives (Lutgen-Sandvik, Namie \& Namie, 2009).

For a situation to be regarded as workplace bullying, three distinctive considerations should be met. Firstly, workplace bullying is identified in terms of a prolonged frequency of conflict or persistent pattern of harmful behaviour (Cunniff \& Mostert, 2012; Jerkins, 2011). Secondly, it entails a situation where victims experience psychological and/or physical harm (Dzurec et al., 2017). Lastly, the victims are considered defenceless because they are less powerful than the alleged perpetrator. A power imbalance in the bully-target relationship is therefore an important distinguishing criterion for regarding conflict as bullying (Sheehan et al., 2018).

Workplace bullying can be defined summatively as injurious, hostile or destructive verbal or non-verbal, psychological or physical behaviour (Lutgen-Sandvik, 2008). Such behaviour occurs repetitively, regularly, persistently or systematically over time (Einarsen, Hoel, Zapf, \& Cooper, 2010; LutgenSandvik et al., 2009). The actions are overt or covert (Finchilescu, Bernstein, \& Chihambakwe, 2018) and typically directed from those more powerful to the less powerful at work (Mattice \& Garman, 2010; Salin, 2003). The result is a hostile and intimidating work environment (Von Bergen, Zavaletta, \& Soper, 2006) in which employees' normal work performance and/or health suffers (Einarsen et al., 2010). To be considered inappropriate, behaviour should be regarded as offensive by any reasonable person or be shown to violate accepted social norms (Von Bergen et al., 2006). This explication emphasises that normal day-to-day conflicts and disagreements cannot be regarded as bullying per se. This is the case even though most definitions rely heavily on the perception of individual victims that they are being humiliated, offended, intimidated, violated or made to feel distressed (Von Bergen et al., 2006).

After Adams and Crawford's (1992) book, Bullying at Work: How to Confront and Overcome, systematic research into workplace bullying took flight globally (Zapf \& Einarsen, 2010). Research examined the prevalence and underlying causes of the mentioned phenomenon (Skogstad, Matthiesen, \& Einarsen, 2007), such as the personality traits of targets (Adams, 2000; Balducci, Fraccaroli, \& Schaufeli, 2011). Some reported on the risk of bullying and its destructive effects on organisations' and individuals' well-being (Agtervold, 2007; Hoel, Einarsen, \& Cooper, 2003) and highlighted bullying's direct and indirect financial costs (McCormack, Casimir, Djurkovic, \& Yang, 2009). Others focused on relevant educational or prevention strategies (Vartia \& Leka, 2011). Most research has, however, been occupied with the difficulties in pinpointing the act of bullying. This is accomplished, on the one hand, by focusing on conceptualising the phenomenon as such (Einarsen et al., 2010) and on the other hand by distinguishing it from related constructs such as workplace victimisation, violence and harassment (Cunniff \& Mostert, 2012; Momberg, 2011; Pietersen, 2007). Despite different approaches, studies emphasise that the targets are humiliated and demotivated; thus, productivity and the organisation's 'bottomline' are impacted negatively (Sheehan et al., 2018).

In South Africa, Marais-Steinman (1998) is considered a pioneer in the field for identifying workplace bullying in various occupational sectors (Cunniff \& Mostert, 2012). Numerous studies followed within the South African work context. Burton (2001), for instance, views workplace bullying as a subset of workplace violence. Pietersen (2007) conceptualised bullying as persistent, inappropriate verbal and non-verbal behaviour resulting from interpersonal issues between people. He highlights the relational aspect of the phenomenon and found that bullying can be directed from a superior to a subordinate or vice versa. De Wet (2010) confirmed the distinctive characteristics of bullying as conceptualised by Pietersen. In addition he found that bullying negatively affected the victims' performance and work well-being and that it caused employee relations to break down. Momberg (2011) investigated the prevalence 
and consequences of bullying and found that various internal and external recourse mechanisms are available to victims of workplace bullying, but most of these are not effectively applied. Momberg proposed the development of a Code of Good Practice in Dealing with Workplace Bullying in terms of Section 54 of the Employment Equity Act of 1998.

From their side, Cunniff and Mostert (2012) focus on the prevalence of workplace bullying across various industries and report that over $31.1 \%$ of their sample $(n=13$ 911) experienced bullying at work with negative physical and psychological effects. Cilliers (2012) examines organisational bullying experiences from the perspective of system psychodynamics and contributes to understanding the phenomenon better by highlighting the unconscious behavioural dynamics that result in subtle forms of bullying such as humiliation, intimidation and insults. More recently, Coetzee and Van Dyk (2018) confirmed the negative effect of workplace bullying on turnover. Other studies show that psychosocial flourishing (Coetzee \& Oosthuizen, 2017) and certain personality traits (Omar, 2017) can only partially alleviate this negative effect. Finchilescu et al. (2018) also indicate that social support does not significantly mediate the effect of high-level workplace bullying on mental well-being.

Training in conflict management, interpersonal skills and types of bullying behaviour have been the most common intervention method to curb bullying in organisational contexts (Einarsen et al., 2018; Jackson et al., 2014; Khan \& Khan, 2012). According to Van den Broeck, Baillien and De Witte (2011) proper job design to control for critical job demands and to reinforce job resources for vulnerable employees is a preventative strategy that some organisations follow. The potential for bullying is also more effectively prevented when organisations establish a well-being policy with relevant wellness activities (Heizmann \& Fox, 2017; Nzonzo, 2017). Yet, solely relying on an anti-bullying policy is inadequate in preventing and dealing with bullying (Balducci et al., 2011; Ryan, 2016). Anti-bullying policies are more effective in organisations where they are linked with additional intervention processes such as bullying awareness campaigns and available support mechanisms, for example, counselling and mentoring (Balducci et al., 2011) and a dedicated ombudsman (Ryan, 2016).

Collectively these studies demonstrate that workplace bullying is a pervasive and contentious phenomenon within the South African work context. Bullying is costly to both the individual and the organisation because of negative consequences for work performance as well as its detrimental effect on employees' and the organisation's well-being and workplace relations. To curb bullying in the workplace, training, policy and additional proactive intervention mechanisms should be in place. The prevalence of bullying and its dire consequences require continued research (Ncongwane, 2010; Omar, 2017; Salin et al., 2018) and increased organisational attention (Coetzee \& Oosthuizen, 2017). The reason is that such bullying is regarded as one of the most serious workplace problems in the new millennium (Steinman, 2009), damaging the organisation's bottom line (Mattice \& Garman, 2010).

\section{The intricate role of the human resources practitioner}

In their overall objective to maintain relations among employees (Sheehan, De Cieri, Cooper, \& Shea, 2016), HR practitioners fulfil work roles filled with paradoxical stakeholder demands (Collings et al., 2018; O'Brien \& Linehan, 2014). Human resources practitioners' roles are complicated foremost by the different constituencies they serve (Sheehan et al., 2016). Constituencies include employees as well as line and top management, each with unique and frequently conflicting expectations, which may cause role conflict and ambiguity for the HR practitioner. Intrinsic to HR practitioners' roles, they also have to navigate relational power differences among these constituencies (Heizmann \& Fox, 2017). Naturally this creates emotional demands in their daily functioning - stressors that often are ignored (O'Brien \& Linehan, 2014).

Employees expect the HR practitioner to care for and champion their needs in the organisation (O'Brien \& Linehan, 2014). When individuals experience unfair treatment, they expect the HR practitioner to intervene, providing fairness and justice (Fox \& Cowan, 2015). Aggrieved employees often become impatient and frustrated, thus directing their negative emotions towards the HR practitioner. Jamrog and Overholt (2004) also point out that management often expects HR practitioners to go beyond their normal day-to-day administrative duties. This means these practitioners must provide expertise on resolving difficult workplace issues, thereby leading to role conflict and demanding emotional work for the HR practitioner. In this regard, HR practitioners are pressured to refrain from expressing their negative emotions to their constituents, which may have detrimental effects on their performance and well-being ( $\mathrm{O}^{\prime}$ Brien \& Linehan, 2014).

In addition to the paradoxical expectations and emotional work inherent to HR practitioners' role, their subordinate power position in the organisation leaves them with a lack of adequate decision-making power to manage difficult workplace issues such as bullying (Collings et al., 2018; Gill, 2017). There is a general premise that as strategic business partners, HR practitioners have as much power as top management to resolve employees' work-related problems (Namie \& Lutgen-Sandvik, 2010; Salin, 2008; Sheehan et al., 2016). Human resources practitioners' decisions, however, have to be ratified by top management (Gill, 2017), and they merely implement management's decisions (Grobler, Warnich, Carrell, Elbert, \& Hatfield, 2012). The reality is that HR practitioners hold a subordinate power position in organisations (Namie \& Namie, 2011), and the HR function continues to negotiate its legitimacy within the organisation's strategic value chain (Davis, 2017; Heizmann \& Fox, 2017; Sheehan et al., 2016). 


\section{Research design \\ Research approach}

Qualitative research is particularly valuable when studying sensitive behavioural phenomena such as workplace bullying (Fahie, 2014). This interpretive, qualitative inquiry was directed ontologically by the notion of critical realism (Redman-MacLaren \& Mills, 2015) together with a constructivist epistemology (Crotty, 2005). An interpretive stance seeks to create exploratory and descriptive knowledge and in-depth understanding of people's lived experience and shared meaning of a particular phenomenon within a specific context (Terre Blanche \& Kelly, 2004). Such an approach to research supports the idea that a study's findings contribute to a knowledge domain by representing a version of the truth and that such findings should be aimed at critiquing and transforming the status quo (Redman-MacLaren \& Mills, 2015). The findings presented here, therefore, do not claim an absolute truth but propose a perspectival account of HR practitioners' role in workplace bullying to create a critical awareness of the context-specific dilemmas they face. The aim is to influence changes in policy and management that would help empower these practitioners in the key role they fulfil.

\section{Research strategy}

The study was designed on the basis of a constructivist grounded theory (Charmaz, 2006, 2014). This allowed for the application of classic grounded theory methods to develop themes that are grounded in data and in the cocreation of meaning between researcher and participants (Charmaz, 2006, 2014). The grounded theory strategy entailed constructing themes through simultaneous gathering and analysing of data, theoretical sampling and an iterative inquiry process (Birks \& Mills, 2015; Glaser \& Strauss, 1967).

\section{Research methods}

\section{Research setting}

The research focused on practitioners from the HR service departments of two institutions of higher education. The HR departments service these institutions through various functions such as staffing, HR development, compensation and benefits, promoting employees' health and wellness, as well as the management and administration of grievances.

\section{Entrée and establishing researcher roles}

The HR executive director and the Senate Research and Innovation Committee acted as gatekeepers and granted the researchers access to their HR practitioners' contact details. These practitioners were recruited for the study through telephone and emails. Prior to commencing with interviews, practitioners were informed fully about the nature of the study and its topic. Participation was voluntary, and practitioners gave written informed consent before the fieldwork started.

\section{Research participants}

Purposive sampling was applied to identify participants who would purposefully inform an understanding of the research problem and the phenomenon central to the research objective (Creswell, 2013). Criteria for such sampling, also referred to as 'inclusion criteria' (Omona, 2013), were set to capture information-rich data and ensure reputable participants from the phenomenon under research (Etikan, Musa, \& Alkassim, 2016). According to these criteria, participants were eligible for the study if they had been employed permanently in an HR position, with a minimum of 3 years' HR experience, and were performing general HR responsibilities.

In grounded theory studies, samples are usually not large (Charmaz, 2014; Mason, 2010). The sampling process is flexible and iterative, guided by theoretical sampling (Birks \& Mills, 2015). Data analysis commenced after the first two interviews. Further participants were added and follow-up interviews conducted, based on the theoretical sampling principle of ongoing theory development. When we reached a point when no new insights emerged from the data, we did not sample further participants. The sample, as depicted in Table 1, ultimately included nine HR practitioners, four being male and five female. The professional affiliation of each research participant (RP) is indicated in the table as being either to the South African Board for People Practices (SABPP) or to the Industrial Relations Association of South Africa (IRASA). Five participants were black, two white, one mixed race and one Indian. Their educational qualifications ranged from a diploma to a doctoral degree. Two of the nine participants were managers in their HR subunits; three were team leaders and the remaining four were practitioners who report to team leaders and/or managers. Two participants attested to having 3-5 years of

\begin{tabular}{llllll}
\multicolumn{1}{l}{ TABLE 1: Profile of sample $(n=9)}$. \\
\cline { 2 - 6 } & Gender & Race & Job title/position & Organisational tenure & Qualification \\
\hline RP1 & Male & Black & Team Leader & 8 & Honours degree \\
RP2 & Male & White & Manager & 15 & Master's degree \\
RP3 & Female & White & Manager & 18 & SABPP \\
RP4 & Female & Black & Team Leader & 12 & SABPP \\
RP5 & Female & Black & Practitioner & 6 & B.Tech degree \\
RP6 & Female & Mixed race & Practitioner & 3 & Honours degree \\
RP7 & Male & Black & Practitioner & 18 & Diploma \\
RP8 & Male & Black & Team Leader & 20 & Diploma \\
RP9 & Female & Indian & Practitioner & 5 & Degree
\end{tabular}

RP, Research participant; SABPP, South African Board for People Practices; IRASA, Industrial Relations Association of South Africa. 
HR experience, two had 6-10 years and five had between 11 and 20 years' experience.

\section{Data collection}

Semi-structured interviews allowed for an emergent understanding of HR practitioners' experience of workplace bullying in a real-life setting. An interview guide was constructed with opening questions aimed at building rapport and getting to know the background of the participant as an HR practitioner. Key questions were formulated to probe the participants' accounts of workplace bullying incidents he or she had to deal with. Probing questions explored the cognitive, affective and behavioural responses of the participant in relation to the bullying cases. The interview was closed with a question on whether the participant wanted to add anything. Interviews lasted between 50 minutes and 55 minutes and the decision to conclude the data gathering was informed not by the amount of data but rather by its richness, through constant comparison of the emerging information in relation to the research objective (Glaser \& Strauss, 1967; Guest, Bunce, \& Johnson, 2006). Follow-up interviews were conducted with all the participants to clarify the researchers' understanding of issues emanating from the first interview and where necessary to probe further experiences. These typically lasted approximately $30 \mathrm{~min}$.

\section{Data recording}

After gaining consent from participants, interviews were audio-recorded. Recordings were transcribed verbatim by a professional transcriber. Transcription accuracy was checked by listening to the recordings repeatedly and simultaneously reading through the transcriptions. Lengthy processing of the data in this way aided immersion in and familiarity with the data.

\section{Data analysis}

Data analysis commenced directly after the initial interview and continued consecutive to each interview (Charmaz, 2006). In grounded theory analysis, meaning is iteratively ascribed to data during different coding stages by the method of constant comparison, where codes are advanced conceptually through the practice of memoing (Birks \& Mills, 2015). The coding process used in the present study was guided by the analytic approach of Charmaz (2006). This involved the stages of open, axial and theoretical coding. Open coding entailed deconstructing the data by constantly comparing it with the research objective and labelling meaningful data pieces as 'codes'. Meaningful data reduction was further done in the next axial coding stage, by identifying relationships, similarities and contradictions between codes, which help construct categories of meaning. Theoretical coding followed, during which four core themes were constructed, by integrating categories conceptually in comparison to one another and to existing literature (Charmaz, 2006). Moving iteratively to and fro in this coding process, ATLAS.ti software was used to manage the constant comparison between field notes, conceptual memos, emerging codes, categories and themes.

\section{Ethical considerations}

Permission to conduct the study as well as ethical clearance was obtained from both institutions under study (Reference: REC2013/01/001 and SENRIC 30 November 2012). To guard the anonymity of the participants and ensure confidentiality in light of the sensitive issue under inquiry, the specific institutions are not named.

\section{Findings}

From the empirical analysis several categories or subthemes emerged, which were grouped, and four key grounded theory themes were constructed. The themes describe the dilemmas faced by the HR practitioners from their workplace bullying experiences. These themes were: role ambiguity: torn between paradoxical constituent demands; power dynamics and lack of authority in the HR role; HR selfefficacy negatively affected by a lack of policy; and management's disempowering orientation towards bullying.

\section{Role ambiguity: Torn between paradoxical constituent demands}

The participants were acutely aware of their commitment to both complainants and perpetrators. Thus, they found themselves torn by the pressure of attending to opposite sides of the bullying narrative. Such ambiguity made it difficult for HR practitioners to distinguish the truth and act objectively in a situation where bullying occurs:

'As an investigator, being impartial or neutral is difficult. It's extremely difficult to detect and assess the gist of the situation because people will do anything or use any means available to defend themselves or others in order to skew your conclusion to their favour.' (Research participant [RP] 7)

In a similar vein, RP2 recognised the effect of a subjective perspective when diagnosing a situation as workplace bullying: 'I think there is a very thin line between bullying and perceived bullying. People should be very careful to make distinctions about intended bullying behaviour'. As a result, participants attempted consistently to determine actual intent from the accused: 'I focus on the purpose or intent' (RP1). However, they simultaneously emphasised the difficulty of determining intent: 'Well, I looked for the intention, though sometimes it is complicated to determine intentionality' (RP4).

Human resource practitioners found themselves undecided on who to believe - the target experiencing bullying or the accused denying intent. This made it difficult to trust their own impartiality and ability to address the situation effectively. Research participant 8 described how the obscure nature of a bullying situation affects his objective response:

'Maintaining impartiality in this institution is not always conceivable because if bullying involves subordinates or just 
employees, the line managers are quick to act in the best interest of the institutions, but if it involves one or more of the middle or top management or their protégés they act otherwise.

Based on these responses, it is also evident that the HR practitioners' role to help address the bullying situation is complicated because they serve both employees and management. This implies serving the conflictual expectations of both the target and the bully, especially as targets frequently accuse their supervisors or managers of bullying behaviour. Thus, both parties make it difficult for the practitioner to assess and act clearly. Research participant 4 explained: 'In cases where senior employees or their favourite staff are involved, decisions taken are biased'. He, however, also recognised: 'Very often targets complicate our role and they do not understand. They feel frustrated because they expected us to stop it just like that'.

In the context of being torn between constituents' paradoxical demands, RP5 summarises the difficulty of having to address bullying: 'Affording both parties the opportunity to state their side without judging either target(s) or accused is difficult'. This is often because of the highly subjective nature of the bullying experience:

'As an investigator you need to find the truth or get to the bottom of a problem because bullying is subjective and difficult to prove sometimes; because some people will do anything to get a person out of their way for good and because of their inferiority position, fear of reprisal or they want to gain something.' (RP8)

These responses reflect the psychological and emotional pressure HR practitioners feel: being torn between their commitment to serve employees, line managers and the organisation overall. This paradoxical commitment makes them feel pressurised and uncertain when diagnosing and addressing a situation such as bullying. In several cases, this ambiguity disables the HR practitioners from acting, or causes them to act destructively, as noted by RP4: 'This behaviour induced us to take fake sick leaves just to avoid being pushed around'.

\section{Power dynamics and lack of authority in the human resources role}

Literature indicates disproportionate power relations as a defining component of workplace bullying (Dzurec et al., 2017; Lutgen-Sandvik et al., 2009; Von Bergen et al., 2006). The findings in the present study show that power is a core issue. The results also uniquely highlight how the HR practitioners' advisory role and consequent lack of decisionmaking authority entangles them in the bullying dynamic. To illustrate, some participants narrated how line managers, for example, often intimidated them by reminding them of their inferior positional authority. Research participant 4 reflected on how his line manager instructed him to deal with a specific complaint: 'I am your team leader and you will do as I tell you'. Having submitted an investigation on a specific case, RP7 experienced his lack of authority to act when he attempted to follow-up: 'I was told the investigation is underway and you will be informed of the outcome, but you never hear from them'. Ultimately, the HR practitioners lack decision-making authority in several respects and mainly function in an advisory role: 'My role is to advise employees and the management based on formal documents or guidelines available and that's it' (RP2).

Research participant 6 indicated the approach of line managers who 'deliberately make them [HR practitioners] feel on edge about the promotional prospects or whether their job is secure or not'. A continuous lack of decision-making power causes HR practitioners to be compliant with managerial requests because they fear punishment. In this regard, the response by RP8 emphasises the HR practitioners' fear of acting in the context of power affiliations: 'Myself and other colleagues are careful in responding to such $[a]$ bullying colleague because he or she knows how to push the line manager's weight around'. Because of such power dynamics, HR practitioners feel that bullies carry on with their behaviour unchallenged. Thus, fearing their own position, the HR practitioner feels incapable of mitigating or stopping bullying. Research participant 2 describes the HR practitioners' inability in this regard: 'Such individuals like [to] get things done their way at the expense of others and you cannot defy or confront because of their top position'. In this way the HR practitioners seem to become despondent and even distrustful of management, to the extent that they start to feel that they themselves are being bullied by management. Feeling bullied by management is reflected in the threat that underlies the response of RP3: 'These individuals meddle with every day-to-day business of departments and expect us to do as he/she says or else'.

Participants pointed out their inability to stand up against a perpetrator who occupies a more powerful position than the HR practitioner. As a result, the victim (i.e. employee) tends to perceive the HR practitioner as siding with the perpetrator (i.e. manager). Thus, victims label these practitioners as incompetent (Namie \& Lutgen-Sandvik, 2010) or exasperating the situation (Ritzman, 2014). In this power dynamic, the HR practitioner not only feels bullied by management but also by the employees, as reflected on by RP8: 'It becomes problematic to deal with and there is nothing we could do in the situation; and that often makes us become victims and targets become bullies themselves'. These responses reveal the paradoxical demands of constituents, which manifest in an intricate power dynamic. This state of affairs complicates the role of the HR practitioners to such an extent that it thwarts their ability to deal effectively with complaints of workplace bullying.

\section{Human resources self-efficacy negatively affected by lack of policy}

All the HR practitioners in the present study were unaware of a bullying policy in their organisations and mostly referred to the sexual harassment policy. Research participant 2, for instance, indicated:

'I am not aware of $[a]$ bullying policy, to the best of my knowledge, and never saw it. The management sometimes use the harassment policy and/or code of conduct or the employee 
disciplinary code to address misconducts but with bullying problems these documents fail to address bullying objectively and often the decision taken is not fair.'

In performing his duty to investigate grievances of bullying, RP8 voiced his frustration with the lack of clear guidelines and management's negative attitude in this regard:

'I searched for the definitions of bullying and made recommendations to the senior management committee to amend and add certain terms to the harassment policy to include harassment part A and bullying part B. But the response I got from the management committee was negative.'

When there is a lack of clear policy, HR practitioners run the risk of being subjective in their diagnosis and consequent handling of a bullying situation. This subjective view is reflected pertinently in the reasoning of RP5:'I think I know and can feel when they are bullying'. Human resources practitioners believe that the absence of a policy about bullying or formal guidelines makes it difficult for them to identify and handle situations where bullying occurs. Research participant 6 explained: 'A policy is needed to address some of these behaviours because it makes us uncomfortable each time I meet with these colleagues'. Research participant 8 maintained: 'Availability of a bullying policy will give them [HR practitioners] power to deal with bullying situations, protect the target and witness, and also leverage to hold top management accountable should they overstep the policy'. The results thus showed that the participants were unaware of a policy governing bullying.

\section{Management's disempowering orientation towards bullying}

The HR practitioners noted their perception of management's evasive position in the bullying dynamic. For participants, managerial attitude was key to their own capacity to address bullying complaints. Managers seem to discount the prevalence of bullying or to shy away from such incidents. The reason may be that this is a sensitive issue or because managers are frequently pointed out as the perpetrators (Cunniff \& Mostert, 2012). Consequently, participants felt unsupported by management and perceived management to deny or suppress the high frequency of bullying situations: 'They hate to deal with bullying situations. They [would] rather postpone it or justify it as a misunderstanding or personality difference to get rid of it' (RP8). Research participant 9 asserted: 'I have witnessed several times some employees in management positions getting away with bullying; they excuse it as misunderstanding'. Furthermore, participants pointed out: 'If you report a bully to the management or a person above, they tell you this matter will be investigated and then you never hear from them' (RP4). When HR practitioners were asked how management responded to bullying complaints, RP4, RP5 and RP8 emphasised apparent disinterest and an interest mostly in quick solutions. Similarly, RP3 stated: 'They are interested in quick solutions. Who gets hurt in the process is none of their business, HR should deal with it'. Research participant 1 remarked: 'On paper they are committed, but practically they are not'. These findings are consistent with those of Samnani and Singh (2012) that the inability of those in leadership positions to recognise workplace bullying and deal with it often makes it difficult to pin down such behaviour, in this context particularly for the HR practitioner.

Based on their experience of management's disengagement in bullying situations, HR practitioners asserted that management allows bullying to become infused in the organisational culture:

'Bullying behaviours are features of an institution's culture and are twisted by those leading the departments and institution, because a culture is developed, endorsed and instructed by the top management. And this determines how their employees are managed.' (RP8)

Furthermore, it was pointed out: 'Bullying is used as a strategy espoused in organisational culture and that culture originates from the top' (RP1). In this manner the participants perceived a bullying culture to be perpetuated and extended across the departments by those entrusted to develop, approve and implement organisational culture.

Management's evasive or negative attitude towards bullying can be understood when reflecting on the accused's position, which managers frequently occupy in the bullying complaint (Cowan, 2012). This presents the manager with an obvious conflict of interest. Two HR practitioners from both organisations noted similar situations where employees felt uncomfortable and intimidated when they had to follow the grievance procedure through management. This was especially because the alleged bullies were part of the grievance structure or close to their immediate superiors. In this regard, Yamada (2008) argues that top management has a significant influence on the bullying that is perpetuated in organisations, especially through attitudes that disregard the importance and prevalence of such behaviour (Skogstad, Einarsen, Torsheim, Aasland, \& Hetland, 2007).

Finally, RP4 reflected on the de-authorising effect that management's conflicted interest exerts on the HR practitioner: 'In some situations where the management is biased or retributive and does not want to be seen as biased or retributive, the management see us not as advisors to them'. The participants' perceptions in this regard confirms the opinion of Sumner, Scarduzio and Daggett (2016) that management often fail to treat workplace bullying seriously. Management's ambiguous position in the bullying dynamic disempowers the HR practitioners, thus preventing them from addressing complaints effectively.

\section{Discussion}

The HR practitioner is generally acknowledged as an integral actor in a situation where bullying occurs (Cowan, 2012). Nevertheless, research to date has largely omitted an HR perspective on workplace bullying (Salin et al., 2018). The present study was concerned with the HR practitioners' 
perspective on workplace bullying in order to shed light on the dilemmas these practitioners face when having to deal with bullying in the workplace. The findings show that HR practitioners are involved intricately in addressing complaints about workplace bullying. However, these practitioners experience several difficulties that prevent them from dealing effectively with these complaints, which include role ambiguity, complex power dynamics and lack of authority, as well as little guidance because of a lack of policy and management support.

The participants viewed bullying as a complex phenomenon, which is difficult to pin down fairly and objectively. This fear of being unfair and subjective is because in their HR role they serve different client constituencies, who often hold opposing expectations in the bullying dynamic. Thus, HR practitioners are under constant pressure to satisfy the expectations of employees but at the same time to be responsible to the organisation and management. Such a role ambiguity confuses HR practitioners' rational decisionmaking to the extent of paralysis, which reflects the metaphor of Buridan's ass. ${ }^{1}$ This is similar to findings by Cowan (2012) and Sheehan et al. (2016), who note that competing demands by top management, line managers and employees create role conflict and ambiguity for the HR practitioners, making it difficult for the latter to deal with workplace bullying in a self-confident manner.

The paradoxical role of the HR practitioner when serving the interests of employee and management alike is moreover complicated by the complex power dynamic underlying the bullying context. It was found that in most incidences, management are indicated as the perpetrators of bullying or its defenders (Cunniff \& Mostert, 2012; Van Schalkwyk et al., 2011). This sets the scene for power imbalance, not only between the target and the bully but also between the bully, the target and the HR practitioner. Participants in the present study noted how their own lack of authority incapacitated them when having to deal with issues of workplace bullying. The responses reflected the HR practitioners' deficient decision-making power, which on the one hand makes them appear to be siding with the management in the eyes of targets. To solve the bullying complaint in favour of the target is not always possible, especially because these practitioners lack the authority to make certain decisions about bullying complaints. As a result, the victims also perceive the HR practitioners as underplaying or ignoring their concerns (Barrow, 2012). On the other hand, the HR practitioners fear consequences to themselves and feel equally intimidated by management when having to deal with a situation where bullying occurs. Such a feeling of lacking power may prevent them from acting in bullying situations, or when they do they may discover their actions to be ineffective (Lewis \& Rayner, 2003). The subordinate power position of the HR practitioners

1.'Buridan's ass' is an idiomatic expression refering to the dilemma.................. (metaphorically rerred to as a 'donkey' or 'ass') being confronted with two pequally metaphorically referred to as a theortant alternatives. The absence of a clear rationale to choose one above the other leads to indecision (https://www.merriam-webster.com/dictionary/ Buridan's\%20ass) and stress (http://www.pastorbenjamin.com/buridans-ass syndrome/\#.W7Hr9nszapo). thus challenges their self-confidence to address bullying in the workplace, as they find themselves distrusted by the targets and insufficiently authorised to deal with the matter.

For participants in the present study, such an ambiguous situation heightens their stress levels and impedes a positive affect. This finding resonates with that of Sumner et al. (2016) that workplace bullying holds negative psychological consequences not only for targets but for witnesses or bystanders as well. In the present study, such a negative psychological effect is especially evidenced in the HR practitioners' sense of becoming bullied themselves - not only from the perspective of management but also from that of the target. In addition, participants reported indecision and lack of action because they felt inadequate and fearful. Coupled with their paradoxical role expectations, the intricate power dynamic thus creates an untenable position for the HR practitioner, which is further reminiscent of identifying with the paralysed donkey - what we would term 'Buridan's ass' syndrome.

This positioning within the bullying dynamic causes perceptions regarding HR practitioners acting in what Paull, Omari and Standen (2012, p.10) describe as an 'abdicating bystander' role. This also has the unintended consequence that practitioners perpetuate the bullying dynamic as a result of making no useful contribution. Moreover, an HR practitioner risks becoming a fellow victim or 'succumbing bystander' as a result of feeling powerless and incapable of dealing with bullying (Paull et al., 2012, p.13). By performing these roles of 'bullying bystander', HR practitioners experience the rippling effect of the negative emotions linked to the bullying situation. As a result, these practitioners may present typical victim-like symptoms such as anxiety, depression and withdrawal (Paull et al., 2012). Similarly, Cowan (2012) emphasises that HR practitioners' uncertainty in diagnosing bullying affects their sense of self and may lead to stress, tension and ambiguity. These are typical of the stress-related feelings experienced at work that are attributed to Buridan's ass syndrome (http://www.pastorbenjamin. com/buridans-ass-syndrome/\#.W7Hr9nszapo).

Workplace bullying is often framed as an individual or dyadic phenomenon, including interaction between the target and perpetrator (Dzurec et al., 2017; Sumner et al., 2016). However, such a perspective tends to overlook the organisational context and systemic factors that perpetuate the problem of bullying (Einarsen et al., 2010). The HR practitioners' perspectives in the present study emphasise the necessity to recognise an emotionally laden and conflictual relationship triad as fundamental to the bullying dynamic in an organisation. This perspective is coupled with two important factors from within the organisational context. Firstly, in accordance with findings by Fox and Cowan (2015), participants in the present study identified the lack of policy as a key source of their incapability to address workplace bullying. Secondly, in the context of this study, management's perceived evasive stance towards bullying may embed this 
misbehaviour within the organisational culture, which disempowers the HR practitioners from addressing complaints of bullying. Gill (2017) confirms HR managements' power relationship with management as a factor within the organisational context that hinders HR managers' ability to influence strategy and act as change agents in the organisation.

Given HR managements' subordinate power position in the organisation, Gill (2017) argues that management most likely would use the HR practitioners to implement and maintain their utilitarian agenda. In the context of workplace bullying, this leads to dual negative perceptions: the HR practitioners' view of unwilling managerial support, and the employees' assessment of the HR practitioners' unfair handling of complaints. Despite this conundrum, Galang and Osman (2016) found that it is possible for HR practitioners to be both employee champion and strategic partner, if the organisational context empowers and supports their enacting of these roles.

The findings of the present study highlighted the paradoxical duality of the HR practitioners' role, interwoven with a complex triad of power relations and a context that lacks proper policy and perceived managerial support to address bullying. The findings of the present study confirmed those by Branch and Murray $(2015$, p. 289) that workplace bullying is 'multi-dimensional with individual characteristics of targets, perpetrators and bystanders as well as the work environment itself all contributing, synergistically, to its occurrence and escalation'. Combined, the mentioned issues pointed out in this study have an adverse effect on the HR practitioners' ability to manage workplace bullying effectively and competently, resulting in psychological stress, indecisiveness and an inability to act - Buridan's ass syndrome. Consequently, the HR practitioners feel disempowered, victimised and experience work commitments in this regard as distressing. In addition, such an interplay of the mentioned factors seemingly causes HR practitioners to distrust and resent management and, in return, causes employees to distrust and even resent HR practitioners. These findings underline the importance of focusing beyond the dualistic nature of the workplace bullying phenomenon to acknowledge the triadic relationship and organisational context. It is in this that the fundamental dilemma lies for the HR practitioner when required to address bullying effectively.

\section{Implications}

Effective prevention and resolution of workplace bullying cannot be facilitated before acknowledging the fundamental, yet intricate role played by HR practitioners in the bullying dynamic. Occupying a middle ground in a bullying situation is psychologically unhealthy for the HR practitioners, who are working within contradictory role expectations and have to deal with complex power dynamics. These role-related dilemmas disempower the HR practitioner from acting decisively and competently. Perceived lack of policy and poor management support may furthermore often increase the risk that HR practitioners - torn between management and targets - may perceive themselves as victims of bullying. Training and policy are the best means globally to prevent workplace bullying (Salin et al., 2018) yet, according to Sheehan et al. (2018), are insufficient to prevent or even reduce the phenomenon. In this regard, the findings revealed the impetus that is lacking: to develop a comprehensive antibullying strategy that would empower the HR practitioner to effectively deal with bullying at work.

\section{Limitations and recommendations}

Talking about bullying is difficult in the work context, seeing that people are intuitively fearful of reprisal and other consequences detrimental to work relationships (Salin et al., 2018). The sensitive nature of the phenomenon is thus a potential limiting factor per se. This is especially the case in a qualitative study utilising smaller samples and personal methods of data collection (Fahie, 2014). As a result, the participants may have been selective in their disclosure. The researchers were aware of the necessity to methodologically curb this potential limitation, through ensuring ethical and rich data gathering. Therefore, the focus was on establishing and building rapport with participants and ensuring confidential spaces for interviewing them. Follow-up interviews were deemed necessary as well as the decision to review relevant policies. This inquiry was limited to the HR practitioners in two organisations only, and the findings are therefore context-specific.

Continued research is necessary into the perspective of HR practitioners on workplace bullying, to advance an understanding of the following: how bullying manifests and can be recognised; the power dynamics at play; and the recourse alternatives to defuse bullying situations. Such an understanding will contribute to more detailed and specific policy formulations and clear procedural guidelines.

As noted, the findings demonstrate the need for a comprehensive approach to managing bullying within the organisation. Such an approach should incorporate senior and line management to work closely with and support HR practitioners when dealing with bullying issues. Management should be an important precursor in empowering HR practitioners to fulfil their function. The roles of senior and line management, as well as the HR practitioners' role within the bullying dynamic, should be established clearly in policy, seeing that role clarity creates a sense of organisational support and buffers the impact of falling victim to bullying behaviour themselves (Van Schalkwyk et al., 2011). Management training is necessary and should create an understanding of the challenges HR practitioners face in the workplace bullying dynamic. This will facilitate management's commitment to ensuring that these practitioners are skilled, supported and empowered to fulfil their role optimally. A comprehensive strategy should finally include interventions aimed at building $H R$ practitioners' capability and self-efficacy through relevant training and coaching. 


\section{Conclusion}

The complexity of managing workplace bullying for the HR practitioner is exacerbated by being in a paradoxical relationship triad with employees and managers. This practitioner role is moreover impeded by limited decision-making power as well and complicated further by a lack of directive through policy and support from management. Being evasive or ignoring issues of bullying adds to the condition of workplace bullying 'becoming an increasingly silent epidemic' that is underreported because of fear of retribution and lack of perceived support from within the organisation's structure (Van Schalkwyk et al., 2011). Ultimately, it is the organisation's responsibility to protect its employees against bullying and, in the process, assist the HR practitioners, by empowering them through transparency, direction and relevant skills training.

\section{Acknowledgements Competing interests}

The authors declare that they have no financial or personal relationships that may have inappropriately influenced them in writing this article.

\section{Authors' contributions}

M.M. completed his PhD in workplace bullying and wrote this manuscript based on findings from his doctoral thesis. A.B. was the PhD promoter and contributed methodologically and conceptually to the design and findings.

\section{Funding information}

This research received no specific grant from any funding agency in the public, commercial, or not-for-profit sectors.

\section{Data availability statement}

Public sharing of data is not ethically feasible in this study due to the sensitivity of the research phenomenon and the presence of identifiable narrative in the transcripts. To ensure confidentiality and guard the anonymity of the participants, data is only available on request from and under the supervision of the authors.

\section{Disclaimer}

The views expressed in the submitted article are the authors' own and not an official position of the institution(s) at which the research was conducted or with which the authors are affiliated.

\section{References}

Adams, A. (2000). Bullying at work: How to confront and overcome it. London: Virago. Adams, A., \& Crawford, N. (1992). Bullying at work. London, UK: Virago.

Agtervold, M. (2007). Bullying at work: A discussion of definitions and prevalence, based on an empirical study. Scandinavian Journal of Psychology, 48(2), 161-172. https://doi.org/10.1111/j.1467-9450.2007.00585.x
Balducci, C., Fraccaroli, F., \& Schaufeli, W. B. (2011). Workplace bullying and its relation with work characteristics, personality, and post-traumatic stress symptoms: An integrated model. Anxiety, Stress \& Coping, 24(5), 499-513. https://doi.org/10. integrated model. Anxiety, Stress

Barrow, L. M. S. (2012). Workplace bullying and the role of human resource management. Retrieved December 03, 2013, from http://www.hrvoice.org/ workplace-bullying-and-the-role-of-human-resource-management

Birks, M., \& Mills, J. (2015). Grounded theory (2nd edn.). Los Angeles, CA: Sage.

Branch, S., \& Murray, J. (2015). Workplace bullying: Is lack of understanding the reason for inaction? Organisational Dynamics, 44(4), 287-295. https://doi. org/10.1016/j.orgdyn.2015.09.006

Branch, S., Ramsay, C., \& Barker, M. (2007). Managers in the firing line: Contributing factors to workplace bullying by staff - An interview study. Journal of Management \& Organisation, 13(3), 264-281. https://doi.org/10.1017/S1833367200003734

Burton, L. (2001). Violence at work in South Africa. People Dynamics, 24(19), 25.

Charmaz, K. (2006). Constructing grounded theory: A practical guide through qualitative analysis. London, UK: Sage Publications.

Charmaz, K. (2014). Constructing grounded theory. London, UK: Sage Publications.

Cilliers, F. (2012). A systems psychodynamic description of organisational bullying experiences. South Africa Journal of Industrial Psychology, 38(2), 1-11. https:// doi.org/10.4102/sajip.v38i2.994

Coetzee, M., \& Oosthuizen, R. M. (2017). Work-role psychosocial flourishing: Its mediation role on workplace bullying and employee turnover intention. Journa of Psychology in Africa, 27(3), 211-215. https://doi.org/10.1080/14330237.2017. 1321826

Coetzee, M., \& Van Dyk, J. (2018). Workplace bullying and turnover intention: Exploring work engagement as a potential mediator. Psychological reports, 121(2), 375-392. https://doi.org/10.1177/0033294117725073

Collings, D. G., Wood, G. T., \& Szamosi, L. T. (Eds.). (2018). Human resource management: A critical approach. Human Resource Management: A critical approach (pp. 1-23). London, UK: Routledge.

Cowan, R. L. (2012). It's complicated: Defining workplace bullying from the human resource professional's perspective. Management Communication Quarterly, 26(3), 377-403. https://doi.org/10.1177/0893318912439474

Creswell, J. W. (2013). Research design (3rd edn.). London, UK: Sage Publications.

Crotty, M. (2005). The foundations of social research: Meaning and perspective in the research process. London, UK: Sage Publications.

Cunniff, L., \& Mostert, K. (2012). Prevalence of workplace bullying of South African employees. South African Journal of Human Resource Management, 10(1), Art. \#450, 15 pages. https://doi.org/10.4102/sajhrm.v10i1.450

Davis, P. J. (2017). How HR can create competitive advantage for the firm: Applying the principles of resource-based theory. Human Resource Management International Digest, 25(2), 4-6. https://doi.org/10.1108/HRMID-09-2016-0122

De Wet, C. (2010). The reasons for and the impact of principal-on-teacher bullying on the victim's private and professional lives. Teaching and Teacher Education, 26(7), 1450-1459.

Dzurec, L. C., Kennison, M., \& Gillen, P. (2017). The incongruity of workplace bullying victimization and inclusive excellence. Nursing Outlook, 65(5), 588-596. https:// doi.org/10.1016/j.outlook.2017.01.012

Einarsen, S., Hoel, H., Zapf, D., \& Cooper, C. L. (2010). Bullying and harassment in the workplace: Developments in theory, research and practice ( 2 nd edn.). Boca Raton, FL: CRC Press.

Einarsen, S., Skogstad, A., Rørvik, E., Lande, Å. B., \& Nielsen, M. B. (2018). Climate for conflict management, exposure to workplace bullying and work engagement: A moderated mediation analysis. The International Journal of engagement: A moderated mediation analysis. The International Journal of
Human Resource Management, 29(3), 549-570. https://doi.org/10.1080/0958 Human Resource M
5192.2016 .1164216

Etikan, I., Musa, S. A., \& Alkassim, R. S. (2016). Comparison of convenience sampling and purposive sampling. American Journal of Theoretical and Applied Statistics, 5(1), 1-4. https://doi.org/10.11648/j.ajtas.20160501.11

Fahie, D. (2014). Doing sensitive research sensitively: Ethical and methodological issues in researching workplace bullying. International Journal of Qualitative Methods, 13(1), 19-36. https://doi.org/10.1177/160940691401300108

Finchilescu, G., Bernstein, C., \& Chihambakwe, D. (2018). The impact of workplace bullying in the Zimbabwean nursing environment: Is social support a beneficial resource in the bullying-well-being relationship? South African Journal of Psychology, 49(10), 83-96 https://doi.org/10.1177/0081246318761735

Fox, S., \& Cowan, R. L. (2015). Revision of the workplace bullying checklist: The importance of human resource management's role in defining and addressing workplace bullying. Human Resource Management Journal, 25(1), 116-130. https://doi.org/10.1111/1748-8583.12049

Fox, S., \& Spector, P. E. (Eds.). (2005). Counterproductive work behaviour: Investigations of actors and targets. Washington, DC: American Psychological Association. https://doi.org/10.1037/10893-000

Galang, M. C., \& Osman, I. (2016). HR managers in five countries: What do they do and why does it matter? The International Journal of Human Resource Management, 27(13), 1341-1372. https://doi.org/10.1080/09585192.2015.1072099

Gill, C. (2017). Don't know, don't care: An exploration of evidence based knowledge and practice in human resource management. Human Resource Management Review, 28(2), 103-115. https://doi.org/10.1016/j.hrmr.2017.06.001

Glaser, B. G., \& Strauss, A. L. (1967). The discovery of grounded theory: Strategies for qualitative research. Chicago, IL: Aldine. 
Grobler, P., Warnich, S., Carrell, M., Elbert, N., \& Hatfield, R. (2012). Contemporary issues in human resource management: Gaining a competitive advantage. Pretoria, Southern Africa: Oxford University Press.

Guest, G., Bunce, A., \& Johnson, L. (2006). How many interviews are enough? An experiment with data saturation and variability. Field Methods, 18(1), 59-82. https://doi.org/10.1177/1525822X05279903

Heizmann, H., \& Fox, S. (2017). O Partner, Where Art Thou? A critical discursive analysis of HR managers' struggle for legitimacy. The International Journal of Human Resource Management, 28. Retrieved November 05, 2014, from https:// doi.org/10.1080/09585192.2017.1314974

Hoel, H., Einarsen, S., \& Cooper, C. (2003). Organisational antecedents of workplace bullying. In S. Einarsen, H. Hoel, D. Zapf \& C. Cooper (Eds.), Bullying and emotional abuse in the workplace: International perspectives in research and practice (pp. 203-218). London, UK: Taylor \& Francis.

Jackson, S. E., Schuler, R. S., \& Jiang, K. (2014). An aspirational framework for strategic human resource management. The Academy of Management Annals, 8(1), 1-56. https://doi.org/10.5465/19416520.2014.872335

Jamrog, J. J., \& Overholt, M. H. (2004). Measuring HR and organisational effectiveness. Employment Relations Today, 31(2), 33-45. https://doi.org/10.1002/ert.20015

Jerkins, M. F. (2011). Workplace bullying: The perception of the targets, the alleged perpetrator and the HR professional. Doctoral dissertation, University of Adelaide, perpetrator

Khan, A., \& Khan, R. (2012). Understanding and managing workplace bullying. Industrial and Commercial Training, 44(2), 85-89. https://doi.org/10.1108/ 00197851211202911

Lewis, D., \& Rayner, C. (2003). Bullying and human resource management: A wolf in sheep's clothing? In S. Einarsen, H. Hoel, D. Zapf \& C. L. Cooper (Eds.), Bullying and emotional abuse in the workplace: International perspectives in research and practice (pp. 370-382). London, UK: Taylor \& Francis.

Leymann, H. (1990). Mobbing and psychological terror at workplaces. Violence and Victims, 5(2), 119-126. https://doi.org/10.1891/0886-6708.5.2.119

Lutgen-Sandvik, P. (2008). Intensive remedial identity work: Responses to workplace bullying trauma and stigmatisation. Organisation, 15(1), 97-119. https://doi. org/10.1177/1350508407084487

Lutgen-Sandvik, P., Namie, G., \& Namie, R. (2009). Workplace bullying: Causes, consequences and corrections. In P. Lutgen-Sandvik \& B. D. Sypher (Eds.), Destructive Organistional Communication (pp. 41-86). New York, NY: Routledge.

Marais-Steinman, S. (1998). The changing workplace: Work trauma and the workplace. Cape Town: Kagiso Publishers.

Mason, M. (2010). Sample size and saturation in doctoral studies using qualitative interviews. Forum Qualitative Sozialforschung/Forum: Qualitative Social Research, 11(3), Art\#8, 19 pages. https://doi.org/10.17169/fqs-11.3.1428

Mattice, C. M., \& Garman, K. (2010). Proactive solutions for workplace bullying: Looking at the benefits of positive psychology. Paper presented at the International Association for Workplace Bullying \& Harassment, 2-4 June, Cardiff: Wales. Retrieved April 17, 2014, from www.nsea-nv.org/assets/img/content/ BullyingBrochurerevised.pdf

McCormack, D., Casimir, G., Djurkovic, N., \& Yang, L. (2009). Workplace bullying and intention to leave among school teachers in China: The mediating effect of affective commitment1. Journal of Applied Social Psychology, 39(9), 2106-2127. https://doi.org/10.1111/j.1559-1816.2009.00518.x

Momberg, M. A. (2011). The prevalence and consequences of workplace bullying in South Africa. Unpublished Master's thesis. Nelson Mandela Metropolitan University, Port Elizabeth.

Namie, G., \& Lutgen-Sandvik, P. E. (2010). Active and passive accomplices: The communal character of workplace bullying. International Journal of Communication, 4(1), 343-373.

Namie, G., \& Namie, R. (2011). The bully-free workplace: Stop jerks, weasels and snakes from killing your organisation. New York, NY: John Wiley \& Sons.

Ncongwane, S. (2010). The impact and consequences of bullying and violence in the workplace. Retrieved October 16, 2013, from www.hrfuture.net/workplace the workplace. Retrieved October 16,2
bullying and violence/WC1008/htm

Nzonzo, J. C. (2017). A discourse analysis of the exogenous and endogenous drivers of employee wellbeing in South Africa. Australian Academy of Accounting and Finance Review (AAAFR), 3(1), 37-49.

O'Brien, E., \& Linehan, C. (2014). A balancing act: Emotional challenges in the HR role. Journal of Management Studies, 51(8), 1257-1285. https://doi.org/10.1111/ joms.12098

Olweus, D. (1978). Aggression in the schools: Bullies and whipping boys. Washington DC: Hemisphere.

Omar, T. (2017). Workplace bullying, personality and work engagement among South African employees. Doctoral dissertation, WITS, Johannesburg.

Omona, J. (2013). Sampling in qualitative research: Improving the quality of research outcomes in higher education. Makerere Journal of Higher Education, 4(2), 169185. https://doi.org/10.4314/majohe.v4i2.4
Paauwe, J., \& Boon, C. (2018). Strategic HRM: A critical review. In D. G. Collings, G. T. Wood \& L. T Szamosi (Eds.), Human resource management: A critical approach (pp. 49-73). London, UK: Routledge.

Paull, M., Omari, M., \& Standen, P. (2012). When is a bystander not a bystander? A typology of the roles of bystanders in workplace bullying. Asia Pacific Journal of Human Resources, 50(3), 351-366. https://doi.org/10.1111/j.17447941.2012.00027.x

Pietersen, C. A. (2007). Interpersonal bullying behaviours in the workplace. South African Journal of Industrial Psychology, 33(1), 59-66. https://doi.org/ 10.4102/sajip.v33i1.256

Redman-MacLaren, M., \& Mills, J. (2015). Transformational grounded theory: Theory, voice, and action. International Journal of Qualitative Methods, 14(3), 1-12. https://doi.org/10.1177/160940691501400301

Ritzman, M.E. (2014). Human resource professionals and workplace bullying: $A$ systems approach to performance improvement intervention in Criminal Justice Agencies. Unpublished Doctoral dissertation. The University of Toledo, Ohio, United State of America.

Ryan, M. (2016). Management: Besting the workplace bully. Reference \& User Services Quarterly, 55(4), 267-269.

Salin, D. (2003). Ways of explaining workplace bullying: A review of enabling, motivating, and precipitating structures and processes in the work environment. Huma Relations, 56(10), 1213-1232. https://doi.org/10.1177/00187267035610003

Salin, D. (2008). The prevention of workplace bullying as a question of human resource management: Measure adopted an underlying organisational factors Scandinavian Journal of Management, 24(3), 221-231. https://doi.org/10.1016/j. scaman.2008.04.004

Salin, D., Cowan, R. L., Adewumi, O., Apospori, E., Bochantin, J., D'Cruz, P., ... Zedlacher, E. (2018). Prevention of and interventions in workplace bullying: A global study of human resource professionals' reflections on preferred action. The International Journal of Human Resource Management, 29, 1-23. https://doi.org/10.1080/09 585192.2018.1460857

Samnani, A., \& Singh, P. (2012). 20 years of workplace bullying research: A review of the antecedents and consequences of bullying in the workplace. Aggression and Violent Behaviour, 17(6), 581-589. https://doi.org/10.1016/j.avb.2012.08.004

Sheehan, C., De Cieri, H., Cooper, B., \& Shea, T. (2016). Strategic implications of HR role management in a dynamic environment. Personnel Review, 45(2), 353-373. https://doi.org/10.1080/09585192.2017.1406390

Sheehan, M., McCabe, T. J., \& Garavan, T. N. (2018). Workplace bullying and employee outcomes: A moderated mediated model. The International Journal of Human Resource Management, 29, 1-38. https://doi.org/10.1080/09585192.2017.140 6390

Skogstad, A., Einarsen, S., Torsheim, T., Aasland, M. S., \& Hetland, H. (2007). The destructiveness of laissez-faire leadership behaviour. Journal of Occupational Health Psychology, 12(1), 80-92. https://doi.org/10.1037/1076-8998.12.1.80

Skogstad, A., Matthiesen, S. B., \& Einarsen, S. (2007). Organisational changes: A precursor of bullying at work? International Journal of Organisation Theory and precursor of bullying at work? International Journal of Organisation
Behaviour, 10(1), 58. https://doi.org/10.1108/IJOTB-10-01-2007-B003

Steinman, S. M. (2009). What are the causes of workplace bullying? Retrieved May 27, 2014, from http://www.worktrauma.org/survive bully/bullying in_sa.htm

Sumner, E. M., Scarduzio, J. A., \& Daggett, J. R. (2016). Drama at Dunder Mifflin workplace bullying discourses on the office. Journal of Interpersonal Violence, 31 , 1-23. https://doi.org/10.1177/0886260516681158

Terre Blanche, M. S., \& Kelly, K. (2004). Interpretive methods. In M. Terre Blanche \& K. Durrheim (Eds.), Research in practice: Applied methods for the social sciences (pp. 96-123). Cape Town: University of Cape Town Press.

Van den Broeck, A., Baillien, E., \& De Witte, H. (2011). Workplace bullying: A perspective from the Job Demands-Resources model. SA Journal of Industria Psychology, 37(2), 1-12. https://doi.org/10.4102/sajip.v37i2.879

Van Schalkwyk, L. M., Els, C., \& Rothmann, I., Jr. (2011). The moderating role of perceived organisational support in the relationship between workplace bullying and turnover intention across sectors in South Africa. SA Journal of Human Resource Management, 9(1), 1-13. https://doi.org/10.4102/sajhrm.v9i1.384

Vartia, M. A., \& Leka, S. (2011). Interventions for the prevention and management of bullying at work. In S. Einarsen, H. Hoel, D. Zapf \& C. L. Cooper (Eds.), Bullying and harassment in the workplace: Developments in theory, research and practice (pp. 359-379). Boca Raton, FL: CRC Press.

Von Bergen, C. W., Zavaletta, J. R., \& Soper, B. (2006). Legal remedies for workplace Bullying: Grabbing the bully by the horns. Employee Relations Law Journal, 32(3), $14-40$.

Yamada, D. C. (2008). Workplace bullying and ethical leadership. The Journal of Values-Based Leadership, 1(2), 1-13.

Zapf, D., \& Einarsen, S. (2010). Individual antecedents of bullying: Victims and perpetrators. In S. Einarsen, H. Hoel, D. Zapf \& C. L. Cooper (Eds.), Bullying and harassment in the workplace. Developments in theory, research and practice (pp. 177-200). Boca Raton, FL: CRC Press. 